\title{
人の皮膚の散乱位相関数の計測 \\ Measurement of Scattering Phase Function of Human Skin
}

\author{
内藤一夫* 山田純** 小川達弥* 高田定樹*** \\ Kazuo Naito, Jun Yamada, Tatsuya Ogawa, and Sadaki Takata
}

\begin{abstract}
皮膚のふく射伝播は，皮膚を散乱・吸収性をもつ連続媒体と考え，ふく射輸送方程式により取り扱 われることが多い。この式を用いる場合, 式中の減衰係数, アルベド, 散乱位相関数の三つのふく射 物性值により，そのふく射伝播が特徴付けられる。ここでは，これまでほとんど計測されていない人 の皮膚の散乱位相関数を計測できる手法を提案している。この手法では, 放物面鏡と CCD カメラを用 いることで，極短時間で皮膚による散乱光の強度分布を計測し，それを基に散乱位相関数を求める. 実際に, 人工培養した皮膚を対象に, 散乱位相関数を推定した.
\end{abstract}

Radiation transfer in human skin can be represented by the radiation transfer equation (RTE), assuming that human skin is a continuous medium in which the scattering and absorption of light occur. The RTE includes three radiative properties: the extinction coefficients, albedo, and scattering phase function. Among these radiative properties, so far, the scattering phase function has seldom been measured. In this study, we propose an estimation method for the scattering phase function based on the intensity profile of the light scattered by human skin. A system with a paraboloidal mirror and CCD camera was developed to measure the intensity distribution of the light scattered by human skin over a short time, and the scattering phase function of human skin grown in vitro was estimated.

[Keywords: scattering phase function, skin, tissue, radiative property, optical property, radiative transfer]

\section{INTRODUCTION}

Much effort has been made, and is still being made, to understand radiation transfer in human living tissue for medical applications such as skin speckle removal, cancer therapy [1] and optical tissue diagnostics [2]. In addition to the medical field, the cosmetic field is also interested in studying radiation transfer in human skin for the purpose of developing cosmetics.

Human skin consists of three layers: the stratum corneum $(10 \sim 15 \mu \mathrm{m})$, epidermis $(100 \sim 300 \mu \mathrm{m})$ and dermis $(600 \sim 2000 \mu \mathrm{m})$ [3]. When radiation is incident on

* 芝浦工業大学 大学院工学研究科 機械工学専攻、 $\bar{\top} 135-8548$ 東京都江東区豊洲 3-7-5-01i32.

Division of Mechanical Engineering, Shibaura Institute of Technology, 3-7-5 01 i32 Toyosu, Koto-ku, Tokyo, 135-8548 Japan FAX: 03-5859-8001 E-mail: m408042@shibaura-it.ac.jp

** 芝浦工業大学 工学部 機械工学科、 $\bar{\top} 135-8548$ 東京都江東区 豊洲 3-7-5 03d32-b

Department of Mechanical Engineering, Shibaura Institute of Technology, 3-7-5-03d32-b Toyosu, Koto-ku, Tokyo, 135-8548 Japan

FAX: 03-5859-8001 E-mail: jyamada@sic.shibaura-it.ac.jp

***資生堂 ビューティーソルーション開発センター、テ141-0031

東京都品川区西五反田 3-9-1

Beauty Solution Development Center, Shiseido CO., LTD, 3-9-1

Nishigotanda, Shinagawa-ku, Tokyo, 141-0031 Japan

FAX: 03-3490-3946 E-mail: sadaki.takata@to.shiseido.co.jp the skin surface, a part of this radiation is reflected at the skin surface, whereas the rest penetrates into the inner skin. The penetrating radiation is absorbed or scattered by cell membranes, nuclei, other organelles, etc [4]. The absorbed radiation is converted into heat, whereas the radiation that is not absorbed leaves the skin after being scattered numerous times. This kind of radiation transfer in an absorbing and scattering medium can be represented by the radiation transfer equation [5-7]:

$$
\frac{1}{\beta} \frac{d i(s, \boldsymbol{\Omega})}{d s}=-i(s, \boldsymbol{\Omega})+\frac{\omega}{4 \pi} \oint_{4 \pi} p\left(\boldsymbol{\Omega}^{\prime} \rightarrow \boldsymbol{\Omega}\right) i(s, \boldsymbol{\Omega}) d \boldsymbol{\Omega}
$$

where $\boldsymbol{\Omega}$ is the directional vector and $s$ is the location in that direction. When using this equation to analyze the radiation transfer in human skin, three radiative properties have to be assigned: extinction coefficient $\beta$, albedo $\omega$, and scattering phase function $p$ of human skin.

In our previous study [8], an inverse method for estimating the radiative properties of human skin, $\beta$ and $\omega$, was developed and its usefulness was demonstrated. However, with this method, the scattering phase function, $p$, has to be assigned. Marchesini et al. [9] measured the scattering phase function for a human uterus; we used this scattering phase function because reports on the scattering 
phase function for human organs are scarce and we could not find a scattering phase function for the human skin at that time. If a scattering phase function different from that of Marchesini et al. is assigned in the estimation, then the results for $\beta$ and $\omega$ are different. Because the scattering phase function of a human organ distinctly depends on its scatter size, it is considered that the scattering phase function does not depend significantly on a specific part of the body. However, in a series of studies, an estimation of the scattering phase function of human skin is essential in order to estimate reliable radiative properties, that is, the extinction coefficient and albedo.

The scattering phase function is usually estimated based on a measurement result for the angular distribution of the energy scattered by a sample. This requires the development of an optical system with an angle-resolved apparatus. Previous research [9-11] introduced a measurement method that adopted a photodetector or optical fiber that rotated to measure the angular distribution of the energy scattered by a sample. This kind of method requires a long time to measure the distribution of the scattered energy. It is difficult to obtain reliable data because there is a possibility that the radiative properties of the organ will change, and/or that there will be measurement system malfunctions during the measurement, such as fluctuations in the power for the light source, the sensor's sensitivity, and the gain. In addition, the effect of the wavelength on the scattering phase function has not been reported.

The aim of this work was to develop a measurement system for the angular distribution of the energy scattered by human skin over a short time and then to estimate the scattering phase function of human skin at several wavelengths.

\section{MEASUREMENT SYSTEM AND TECHNIQUE}

\section{1 Intensity Profile Measurement for Light}

\section{Scattering by Human Skin}

Figure 1 shows a schematic diagram of the system used to measure the angular distribution of the intensity of light (intensity profile of light) scattered by human skin. To shorten the measurement time, we use a paraboloidal mirror and a CCD camera to measure the intensity profile of the scattered light. A disk specimen of human skin with a diameter of $7 \mathrm{~mm}$ is vertically set at the focal point of the paraboloidal mirror and irradiated perpendicularly by a laser beam projected horizontally, as shown in Fig. 1 . The light scattered by the skin specimen is reflected upward in the vertical direction by the paraboloidal mirror and is incident on a mask above the mirror. The mask has a circular slit so that only the light scattered onto the horizontal plane can pass through it. The light passing through the mask is captured by the CCD camera, and the intensity distribution of the light is stored as a digital image. By analyzing this image, we obtain the intensity profile of the light scattered onto the horizontal plane. Thus, the system enables us to complete the measurement in a short time. The details of the measurement apparatus and skin specimen will be described below.

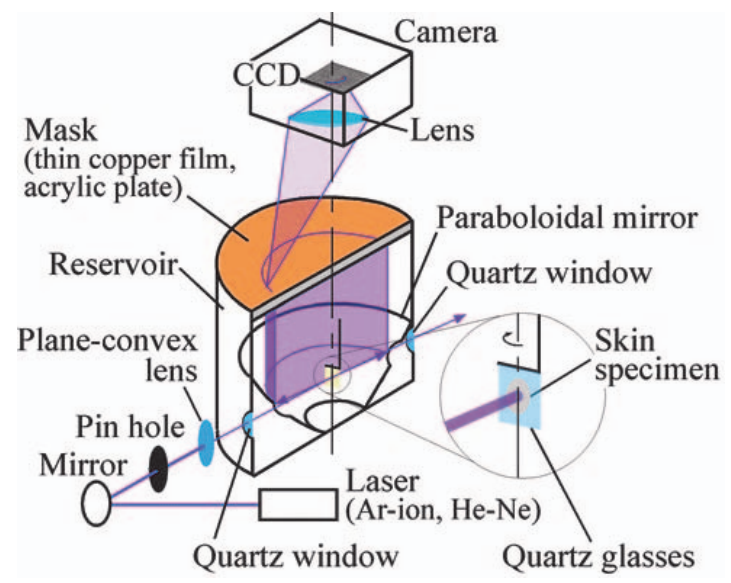

Fig. 1 Cross-sectional diagram of system used to measure angular distribution of scattered light intensity

\section{2 Measurement Apparatus for Scattered Light}

A He-Ne laser $(632.8 \mathrm{~nm}, 30 \mathrm{~mW}$, NEO-30MS, NEOARK Co.) and an Ar-ion laser (457.9 nm, $3 \mathrm{~mW}$; $488.0 \mathrm{~nm}, 25 \mathrm{~mW}$; or $514.5 \mathrm{~nm}, 20 \mathrm{~mW}$, which were selected by dichroic filters, $50 \mathrm{~mW}, 163-\mathrm{D} 02$, Spectra-Physics) were used for the incident laser beam mentioned above. To avoid stray light due to unexpected scattering, each laser beam was focused on the skin specimen to a diameter of $150 \mu \mathrm{m}$ by a plane-convex lens.

The skin specimen was held by two cover glasses made of quartz to maintain its configuration during the measurement, as shown in Fig. 1. Because film spacers were placed next to the skin specimen, the skin was held under little pressure, as shown in Fig. 2.

The refractive index of quartz is 1.46 in the range of visible wavelength, which is an intermediate value for human skin $\left(n_{\text {skin }}=1.37 \sim 1.55\right.$ [12-13], depending on the moisturized condition and/or body site). Therefore, both the refraction and reflection occurring at the interface between the quartz and skin specimen were suppressed. However, if the skin specimen held between two cover glasses was set in the air, reflection and refraction would 
occur at the interface between the air and the cover glasses. Therefore, in this study, we immersed the skin specimen, cover glasses, and paraboloidal mirror in a transparent solution with the same refractive index as the quartz cover glasses. This solution was made of distilled water and glycerin, which were blended to achieve a refractive index that matched that of the quartz glass.

Still, the incident light and scattered light were reflected and refracted at the interface between the air and the solution, because the laser and camera were placed in the air. To avoid the interface effect (the refraction and reflection), two quartz windows with antireflection coating were installed on a sidewall of the reservoir in which the skin specimen and paraboloidal mirror were immersed. The laser beam was focused on the skin specimen in the reservoir through one window and the beam transmitted through the skin specimen exited through the other window located on the opposite side of the reservoir.

The interface effect that occurred when the scattered light passed through the interface between the solution and the air will be described later.

The paraboloidal mirror (Yamada Opt Industrial Co., Ltd.) had an outer diameter of $165.5 \mathrm{~mm}$ and its paraboloidal axis was set vertically. To allow the laser beam to pass in and out, it had two holes on the horizontal axis that ran through its focal point. This axis coincided with the beam axis of the laser running through the two windows on the reservoir.

The disk specimen of human skin was set perpendicular to the above axis (the beam axis of the laser), as shown in Fig. 1. The skin specimen scattered the laser beam in all directions. In this case, any intensity profile for the light scattered onto an arbitrary plane that included the beam axis had the same profile as others, because the skin was symmetrical to the beam axis. Therefore, we focused on the intensity profile on the horizontal plane.

The paraboloidal mirror could reflect the scattered light in the vertical direction, except for the light scattered toward the holes. This system allowed us to measure the intensity profile of the light scattered within a range of polar angles from $8.2^{\circ}$ to $171.8^{\circ}$, which were measured from the direction of the incident laser beam.

As previously mentioned, the mask had a circular slit that only allowed the passage of scattered light on the horizontal plane. The details and features of this mask will be described later.

A CCD (BS40-L, BITRAN Co.) camera with a Peltier cooling system was used to measure the intensity of the scattered light that passed through the slit mask. Before carrying out the measurement, we confirmed the linearity between the light intensity and the stored digital data.

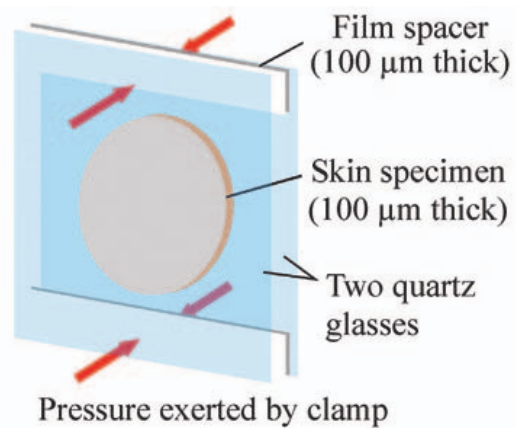

Fig.2 Holder for skin specimen

\section{3 Features of Mask}

The mask played an important role in our measurement apparatus. The mask used in this study was an acrylic plate (SUMIPEX 032, Sumitomo Chemical Co., Ltd.) that had a thin copper film attached to one surface. The thicknesses of the acrylic plate and thin copper film were $2 \mathrm{~mm}$ and $2 \mu \mathrm{m}$, respectively. The acrylic plate included small particles and acted as a diffuser. In other words, the acrylic plate was semitransparent and diffusely transmitted the incoming light.

The original mask had a photo-resist film on the surface of the thin copper film. Using a photolithographic technique, we etched the copper on the mask to draw a circular slit with a diameter of $108 \mathrm{~mm}$ and a width of 1 $\mathrm{mm}$, as shown in Fig. 3. The purpose for using the mask was as follows.

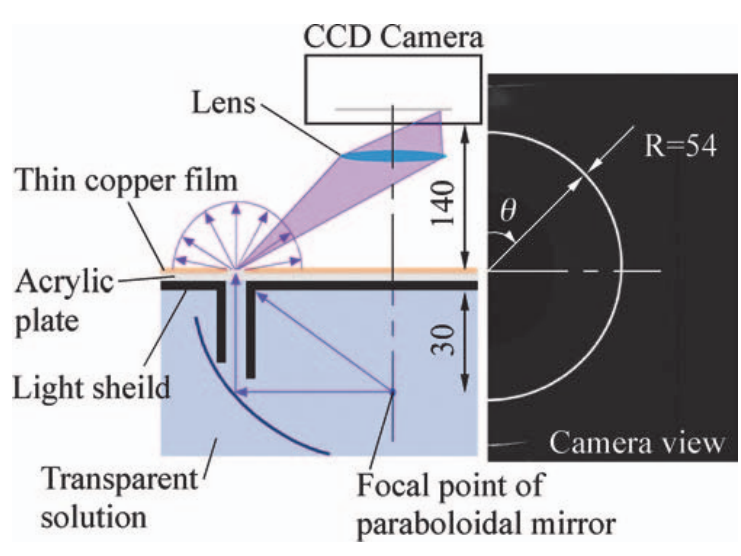

Fig. 3 Lens focused on mask

The primary purpose was to extract the light scattered onto the horizontal plane by a skin specimen. However, if 
this were the sole purpose, the acrylic plate acting as a diffuser would not have been necessary, because a transparent acrylic plate or a glass plate would have served this purpose. However, if the mask did not have the diffuser plate, the light passing through the slit would go straight. In this case, if the detection area of the CCD or the lens of the CCD camera was smaller than the diameter of the slit circle, the light passing through the slit could not be captured by the camera. In the present system, it would be difficult to make the slit circle smaller, and it would not be realistic to use a larger CCD or a larger camera lens. Therefore, we diffused the light as much as possible using the acrylic diffuser plate so that a portion of the transmitted light was captured by the CCD camera, as shown in Fig. 3. When the transmitted light was assumed to be isotropic, we could measure the light intensity proportional to the original intensity of the light hitting the backside of the slit.

Because the slit width affects the angular resolution of the scattered light, it should be as narrow as possible. On the other hand, to obtain enough power from the scattering light, the slit should be wide. A slit width of 1 $\mathrm{mm}$ was determined from a consideration of both effects.

The mask had a light shield on its undersurface so that the light scattered by the skin specimen did not arrive directly at the slit, as shown in Fig. 3.

The camera view of the mask in Fig. 3 is a captured digital image. The white circle shows the light transmitted through the slit. By reading the digital data along the circle, we could obtain the angular distribution of the intensity of the light scattered by the skin specimen.

The backside of the mask was immersed in the glycerin-water solution mentioned above. The refractive index of acrylic is similar to that of the solution. Therefore, significant reflection and refraction did not occur at the undersurface of the mask (the interface between the solution and acrylic plate), but did occur at the upper surface. However, because the reflected and refracted light was very weak, it does not influence the measurement results.

\section{4 Validity of Present Measurement System}

To examine the validity of the present measurement system, a $\mathrm{SiO}_{2}$ fiber with a diameter of around $4 \mu \mathrm{m}\left(n_{\text {fiber }}\right.$ $=1.457$ at $0.63 \mu \mathrm{m}$ ) was used to measure the angular distribution of the scattered light intensity, which was compared with the analytical results computed by the Bohren and Huffman programming code [14].

The fiber was vertically set through the focal point of the paraboloidal mirror. The reservoir was not filled with the solution in this experiment. The He-Ne laser (632.8 nm) was chosen as the incident beam. The incident beam was linearly polarized parallel to the fiber axis in this experiment. When the fiber was irradiated, it scattered the beam onto the horizontal plane. Therefore, the angular distribution of the scattered light intensity could be measured. This measurement was completed within 0.13 $\mathrm{s}$, which was the exposure time of the CCD camera.

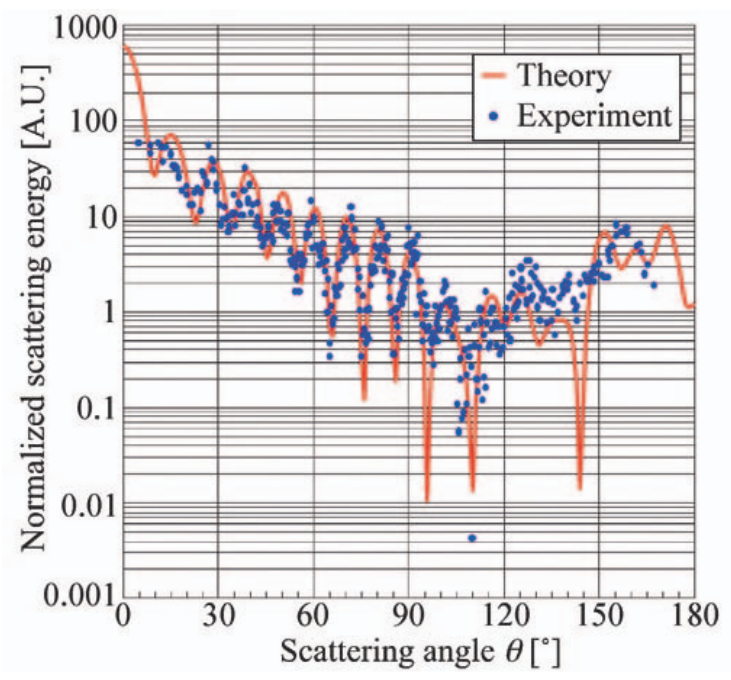

Fig.4 Validity of present measurement system for estimating scattering phase function

The experimental and analytical results are shown in Fig. 4. In computing the analytical result, the fiber diameter was estimated so that the analytical result coincided with the experimental result. The estimated diameter was $3.82 \mu \mathrm{m}$.

For the experimental result, normalization according to the definition of the phase function could not be done because the measurable range for the scattered light was from $8.2^{\circ}$ to $171.2^{\circ}$. Therefore, the absolute magnitude of the experimental result was also determined so that the analytical and experimental results agreed well.

Although the magnitude of the experimental result and the diameter used for computing the analytical result were determined in an inverse analysis manner, they were in good agreement. In addition, it was found that the present system had a high angular resolution and wide dynamic range. Therefore, the present system is considered to be valid for estimating the scattering phase function.

\section{SKIN SPECIMEN AND MEASUREMENT CONDITION}


The definition of the scattering phase function is interpreted as the normalized angular distribution of the intensity of the light that is scattered while an incident light propagates an infinitesimal distance. However, in the measurement, a skin specimen has a finite thickness. For a thick sample, the intensity profile of the scattered light is not proportional to the scattering phase function of the sample, because multiple scattering occurs inside the sample. To determine the effect of sample thickness on the intensity profile of the scattered light, we carried out a numerical simulation of the intensity profile measurement. A Monte Carlo method was employed for this simulation.

In this simulation, we computed the intensity profile of the scattered light that would be measured by the present measurement system for skin samples having various thicknesses. The three radiative properties, $\beta, \omega$, and $p$ were required in this calculation. We used 10.4 $\mathrm{mm}^{-1}$ for the extinction coefficient, $\beta$, and 0.94 for the albedo, $\omega$; these values were measured by the author's group [8]. For the scattering phase function, $p$, we adopted the Henyey-Greenstein (HG) function with the asymmetry factor, $g$ of 0.9 , as shown below.

$$
p_{H G}(g)=\frac{\left(1-g^{2}\right)}{\left(1+g^{2}-2 g \cos \theta\right)^{3 / 2}}
$$

This phase function is often used in numerical simulations of radiation transfer in human skin.

The results are shown in Fig. 5, together with the original phase function. The axis of the abscissa is the scattering angle. The intensity profiles shown here were normalized according to the definition of the scattering phase function. Therefore, in an actual measurement, these correspond to the scattering phase functions that would be estimated by the present method.

It is found that the deviation of the estimated scattering phase function from the original HG phase function increases with an increase in the sample thickness. This is because multiple scattering occurs more easily. However, even the deviation for the $100-\mu \mathrm{m}$ thick sample was as small as the measurement error of the present system. Therefore, a sample with a thickness of less than $100 \mu \mathrm{m}$ is available as a test specimen.

A three-dimensional cultured LabCyte EPI-MODEL, which is an epidermal model of human origin (Japan Tissue Engineering Co., Ltd.), is commercially available. This model is very similar to the human epidermis in terms of anatomy. A model cultured for 6 days was used in the experiment. Before the experiment, the model was soaked in normal saline $(0.9 \mathrm{~g} \mathrm{NaCl} / 100 \mathrm{cc}$ water) for at least $30 \mathrm{~min}$ to standardize the degree of hydration and avoid variation in the radiative properties induced by a difference in water content between epidermal models. Because the thickness of a soaked epidermal model was about $100 \mu \mathrm{m}$ as measured by a micrometer, we used this model as it was.

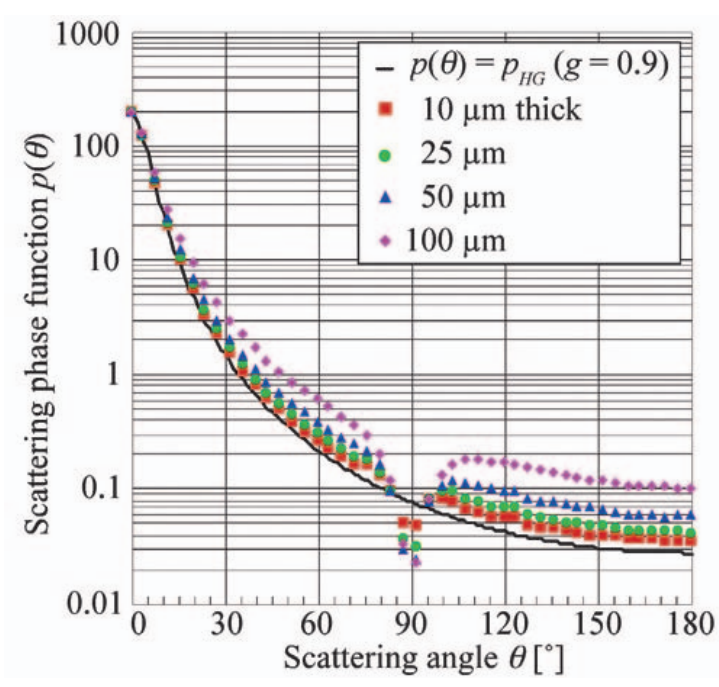

Fig. 5 Effect of sample thickness on estimated scattering phase function

\section{RESULTS AND DISCUSSIONS}

The measurement results for the angular distribution of the scattered radiation are shown in Fig. 6. The measurement times, which are the exposure times of the

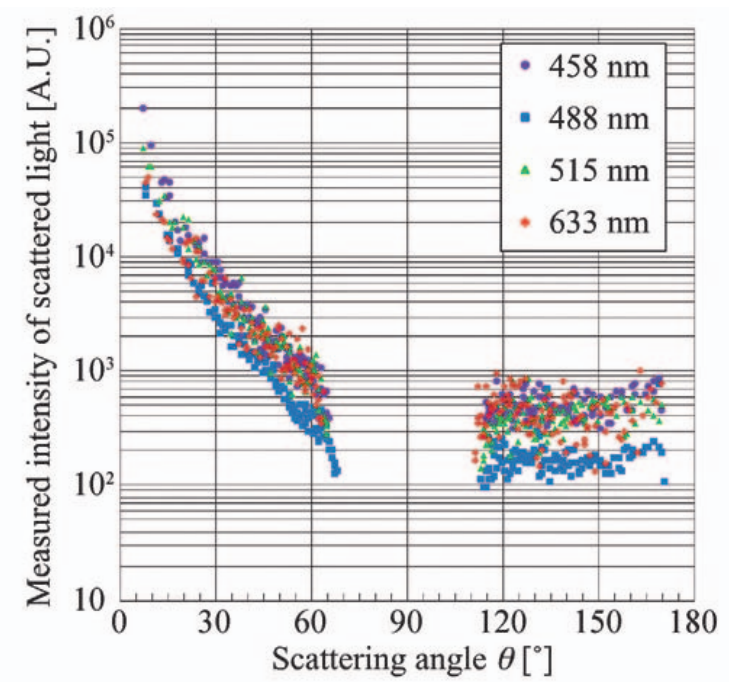

Fig. 6 Measurement results for light scattered by skin specimen 
CCD camera, depend on the radiation intensities of the light sources. The shortest time is less than $1 \mathrm{~s}$ and the longest is about $1 \mathrm{~min}$ in these measurements.

It is found that measurement results around $90^{\circ}$ are missing. The reason for this is that the radiation scattered in the direction of around $90^{\circ}$ propagates in the skin for a long distance and is attenuated. Another reason is that the skin and the quartz glass plates confining the skin have different refractive indexes, which are 1.41 and 1.46, respectively. Due to this difference in the refractive indexes, refraction occurs at the interface between the skin specimen and quartz glass plates, as shown in Fig. 7. The difference in the refractive indexes also causes reflection at the interface. To obtain the original intensity and direction of the scattered radiation, we have to take into account of the reflection and refraction. We correct the measured results by using Snell's law and Fresnel's equations [6].

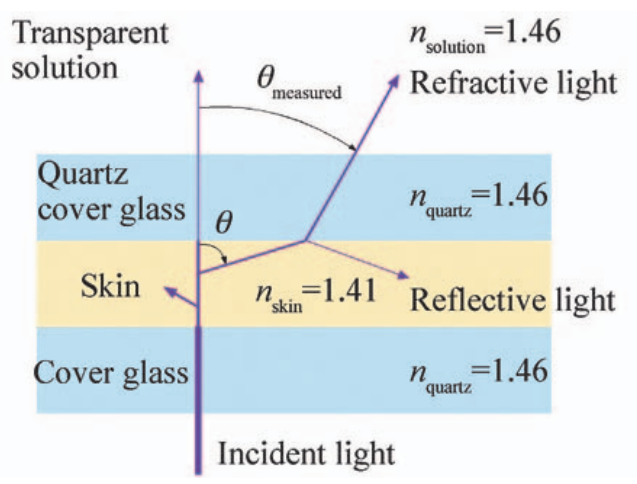

Fig. 7 Refraction and reflection at interface between skin specimen and quartz glass windows

These corrections are made by assuming that the skin specimen is a parallel plate and has smooth surfaces, because the surface of the cultured skin model used in this study seems to be almost flat and smooth from a picture provided by the manufacturer. Even if there are some structures on the skin surface, it is considered that the scattering by these surface structures is much smaller than the internal scattering occurring within the skin, because the difference in the refractive indexes is very small. It is highly unlikely that the surface scattering affects the measured profile of the scattering light.

To calculate the scattering phase function, it is necessary to normalize the angular distribution of the scattered radiation according to the definition shown below. [5]

$$
p(\theta, \varphi)=\frac{i(\theta, \varphi)}{(1 / 4 \pi) \int_{0}^{2 \pi} \int_{0}^{\pi} i(\theta, \varphi) \sin \theta d \theta d \varphi}
$$

where $i(\theta, \varphi)$ is the scattering intensity and $\theta$ is the scattering angle. However, because the radiation scattered in the forward and backward directions, as well as in the direction of around $90^{\circ}$, cannot be measured in this study, we cannot normalize the measured intensities to estimate the scattering phase functions using this equation. In addition, even if the normalization has been made, the normalized results cannot be applied because the measured intensities in some directions are not available. Therefore, we estimate approximate functions based on the measured intensities as described below.

The intensity profile of the scattered light is measured simultaneously at each wavelength. Although the absolute value of the intensity has only arbitrary units, the intensity profile is valid. In this study, based on the intensity profile at each wavelength, we adapt the HG function to the intensity profile using a least square method. However, because a single HG function cannot sufficiently approximate the measured profile of the scattering intensity, two $\mathrm{HG}$ functions are used for approximating the intensity profile at each wavelength. The resultant phase functions are

$$
\begin{aligned}
& \left.\begin{array}{l}
p\left(0^{\circ} \leq \theta<61^{\circ}\right)=0.95 \cdot p_{H G}(g=0.87) \\
p\left(61^{\circ} \leq \theta \leq 180^{\circ}\right)=0.21 \cdot p_{H G}(g=0.30)
\end{array}\right\} \text { at } 458 \mathrm{~nm} \\
& \left.\begin{array}{l}
p\left(0^{\circ} \leq \theta<66^{\circ}\right)=0.97 \cdot p_{H G}(g=0.82) \\
p\left(66^{\circ} \leq \theta \leq 180^{\circ}\right)=0.28 \cdot p_{H G}(g=0.40)
\end{array}\right\} \text { at } 488 \mathrm{~nm} \\
& \left.\begin{array}{l}
p\left(0^{\circ} \leq \theta<57^{\circ}\right)=0.94 \cdot p_{H G}(g=0.82) \\
p\left(57^{\circ} \leq \theta \leq 180^{\circ}\right)=0.31 \cdot p_{H G}(g=0.35)
\end{array}\right\} \text { at } 515 \mathrm{~nm} \\
& \left.\begin{array}{l}
p\left(0^{\circ} \leq \theta<51^{\circ}\right)=0.89 \cdot p_{H G}(g=0.77) \\
p\left(51^{\circ} \leq \theta \leq 180^{\circ}\right)=0.47 \cdot p_{H G}(g=0.36)
\end{array}\right\} \text { at } 633 \mathrm{~nm}
\end{aligned}
$$

These are also shown in Fig. 8 with the measurement results, which are corrected as described above. The absolute values of the measured results at each wavelength are determined so that they agree with the estimated set of HG functions. 


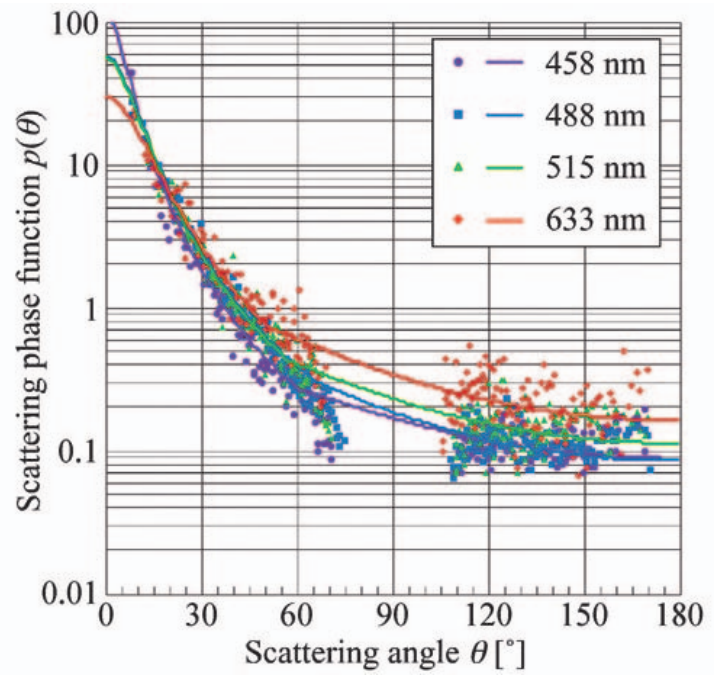

Fig. 8 Estimated scattering phase function

It is found that the forward scattering is strong and the phase functions decrease monotonically with an increase in the scattering angle at any wavelength. It is also found that the estimated scattering phase function slightly depends on the wavelength while the measured data scatter. The forward scattering is strong at a wavelength of $458 \mathrm{~nm}$, and because weaker as the wavelength increases. This can be explained as follows.

Although there are several sizes of scatters in cells, generally speaking, as the size parameter, $\pi d / \lambda$, increases (where $d$ is the size of a scatter and $\lambda$ is the wavelength), the forward scattering gets stronger. This is expected according to Mie theory, which gives details about scattering by spherical particles. It is considered that a similar behavior can be observed in the present results.

At around $0.63 \mu \mathrm{m}$, Marchesini proposed scattering phase functions of human body parts [9] and Jacques also proposed that of human dermis (the third layer of the skin), which was taken from a cadaver [11]. We compared the present results with those reported. The results are shown in Fig. 9. The present resuls are in good agreement with those by Marchesini in the forward direction, but the strong backward scattering that appears in Marchesini's results cannot be seen. On the other hand, Jacque's results are stronger than the others in forward scattering. This might come from the difference in samples. It is necessary to microscopically investigate the scattering in cells to clarify the reason for the difference and/or the agreement.

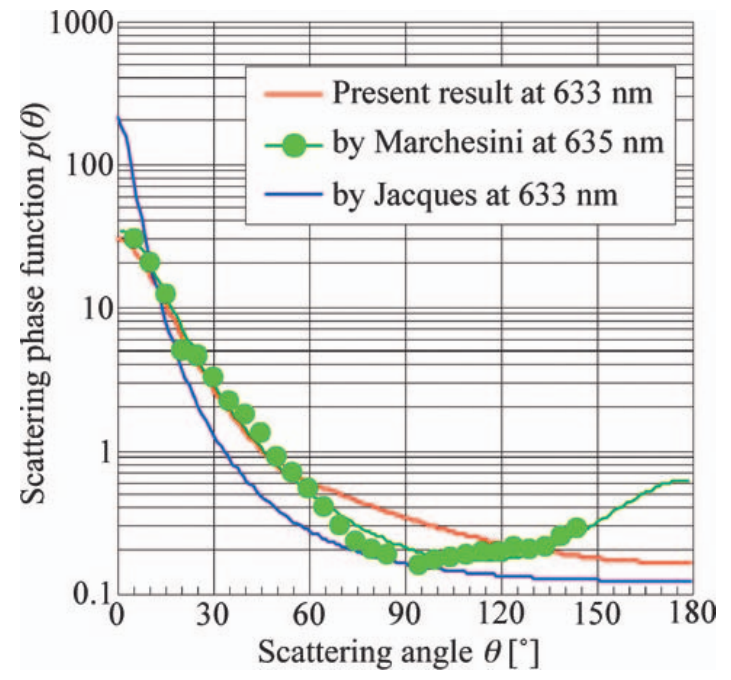

Fig. 9 Comparison of scattering phase functions

\section{CONCLUSIONS}

In this study, a method for measuring the angular distribution of the intensity of the light scattered by human skin in a short time has been proposed and its validity and usefulness verified.

Using this method, we measure the intensity profile of the light scattered by an epidermal model that is very similar to human epidermis (the second layer of skin) and estimate the scattering phase function of the skin in four wavelengths. The epidermal model is not genuine human skin and experimental conditions such as water content are different from the usual conditions for a living skin. However, because the model is anatomically similar to genuine epidermis, it is considered that the scatters in the cells is not different from that in genuine skin. In addition, the water content has little effect on the scattering. Therefore, the scattering phase functions estimated in this study are similar to that of genuine human skin.

\section{[ACKNOWLEDGEMENT]}

This study was supported by the Ministry of Education, Science and Culture of Japan under Grant No. 19360103 and Grant No. 20246039, which the authors gratefully acknowledge.

\section{NOMENCLATURE}

$\beta \quad$ : extinction coefficient, $\mathrm{m}^{-1}$

$i \quad$ : intensity, $\mathrm{W} / \mathrm{m}^{2} \cdot \mathrm{sr} \cdot \mu \mathrm{m}$

$s \quad$ : location in a particular direction, $\mathrm{m}$

$\boldsymbol{\Omega}$ : directional vector, -

$\omega$ : albedo, - 
$p \quad$ : scattering phase function, -

$\Omega \quad$ : solid angle, $\mathrm{sr}$

$n \quad$ : refractive index, -

$\theta \quad$ : scattering angle, ${ }^{\circ}$

$g$ : asymmetry factor, -

$\varphi \quad$ : azimuthal angle,

\section{REFERENCES}

[1] Wilson, B. C., Patterson, M. S.; "The physics of photodynamic therapy", Physics in Medicine and Biology, Vol.31, No.4 (1986), pp.327-360.

[2] Tearney, G. J., Brezinski, M. E., Southern, J. F., Bouma B. E., Hee, M. R., Fujimoto, J. G.; "Determination of the refractive index of highly scattering human tissue by optical coherence tomography", Optics Letters, Vol.20, No.21 (1995), pp.2258-2260.

[3] Tortra, J. G.; "Principles of Human Anatomy", 10th ed. (2004) Wiley, New York.

[4] Mourant, J. R., Freyer, J. P., Hielscher, A. H., Eick, A. A., Shen, D., Johnson, T. M.; "Mechanisms of light scattering from biological cells relevant to noninvasive optical-tissue diagnostics", Applied Optics, Vol.37, No.16 (1998) pp.3586-3593.

[5] Siegel, R., Howell, J. R.; "Thermal Radiation Heat transfer", 4th ed. (2001) Taylor and Francis, New York.

[6] Brewster, M. Q.; "Thermal Radiative Transfer And Properties" (1992) A Wiley Interscience Publication, New York.

[7] Ozisik, M. N.; "Radiative Transfer \& Interactions With Conduction \& Convection" (1985), Welbel \& Peck, New
York.

[8] Yamada, J., Arita, Y., Akihiro, A., Miura, Y., Takata, S.; "Estimation of Radiative Properties for Human Skin by Reflection Profile Measurement", Transactions of the Japan Society of Mechanical Engineers, Series B, Vol.74, No.745 (2008) pp.158-163.

[9] Marchesini, R., Bertoni, A., Andreola, S., Melloni, E., Sichirollo, A. E.; "Extinction and absorption coefficients and scattering phase functions of human tissues in vitro", Applied Optics, Vol.28, No.12 (1989) pp.2318-2324.

[10] Flock, S. T., Willson, B. C., Patterson, M. S.; "Total attenuation coefficients and scattering phase functions of tissues and phantom materials at $633 \mathrm{~nm}$ ", Medical Physics, Vol.14, No.5 (1987) pp.835-841.

[11] Jacques, S. L., Alter, C. A., Prahl, S. A.; “Angular Dependence of HeNe Laser Light Scattering by Human Dermis", Lasers in the Life Sciences, Vol.1, No.4 (1987) pp.309-333.

[12] M. J. C. Van Gemert, S. L. Jacques, H. J. C. M. Sternborg, W. M. Ster; "Skin optics", IEEE Transactions On Biomedical Engineering, Vol.36, No.12 (1989) pp.1146-1154.

[13] R. R. Anderson, J. A. Parrish; "The Optics of Human Skin”, The Journal of Investigative Dermatology, Vol.77, No.1 (1981) pp.13-19.

[14] Bohren, C. F., Huffman, D. R.; "Absorption and Scattering of Light by Small Particles" (1983) Wiley New York.

[Received Feb. 20, 2010, Accepted Apr. 29, 2010] 